\title{
THE EFFECT OF AUTHENTIC LEADERSHIP ON EMPLOYEE PERFORMANCE: A MODERATING ROLE OF ISLAMIC WORK ETHICS Amjad Ali ${ }^{1 *}$, Shahzad Mushtaq ${ }^{2}$, Muhammad Asif ${ }^{3}$, Muhammad Qasim Maqbool ${ }^{4}$, Umer Bin Khalid $^{5}$ \\ ${ }^{1 *, 4}$ Department of Management Science, University of Okara, Pakistan; ${ }^{2,3}$ Department of Economics, University of Okara, Pakistan; ${ }^{5}$ Department of Agricultural Economics, Faculty of Agriculture, Ondokuz Mayis University, Turkey. Email: ${ }^{1 *}$ amjad_jamy81@yahoo.com, ${ }^{2}$ mianb19@yahoo.com, ${ }^{3}$ asifjilinuni88@gmail.com, ${ }^{4}$ qasimmaqbool007@gmial.com, ${ }^{5}$ umer2057@gmail.com
} Article History: Received on $13^{\text {th }}$ February 2021, Revised on $21^{\text {st }}$ March 2021, Published on $24^{\text {th }}$ March 2021

\section{Abstract}

Purpose: This study aims to explore the impact of authentic leadership on employee performance and the moderating role of Islamic work ethics. There is little research on authentic leadership and employee performance in Pakistan's higher education sector. Therefore, the purpose of this study was to analyze the impact of authentic leadership with Islamic work ethics on employee performance.

Methodology: This is a quantitative study. In this study, the convenience sampling method was used as a sampling technique. The data was collected from the higher education sector in Peshawar, and a questionnaire was circulated to 220 employees working in the various higher education sector in Peshawar. Data were analyzed by using SPSS 22 version.

Results: The results show that authentic leadership has a significant impact on employee performance. Authentic leadership also significantly influences IWE. Similarly, the interactive impact of authentic leadership and Islamic work ethics on employee performance was also found to be significant.

Applications of this study: This research can be very effective for improving authentic leadership strategies to improve the performance of employees in the higher education sector in Peshawar, Pakistan.

The Novelty of the study: The contribution of this research is Islamic work ethics using the first time between authentic leadership and employee performance, which has not been used so far. It has been found that Islamic work ethics positively moderate the link between authentic leadership and employee performance.

Keywords: Authentic Leadership, Islamic Work Ethics, Employee Performance.

\section{INTRODUCTION}

An increasingly competitive and dynamic environment requires people to go beyond appropriate employment responsibilities and take active steps to pay their organizations. With the proliferation and decentralization of selfmanagement teams, employee initiative is becoming more and more important to organizational success (Parker and Collins, 2010). According to Morrison (2001), leadership is a key part of a worker's motivation for active behavior. While some researchers have studied the association between exact leader behavior (for example, transformative leadership, empowered leadership) and active behavior (Den Hartog and Belschak 2012; Thomas et al. 2013). However, experimental research is still insufficient, mostly for developing leadership styles (such as authentic leadership). Leadership is very difficult during challenging times, but the only source of stress facing organizations around the world today needs to refocus on true leadership. Leadership scholars believe that authentic leadership has conventional substantive care (Jensen et al., 2006; Walumbwa et al., 2008), who claim that it is very beneficial to the organization and leads to desirable outcomes. Authentic leadership strategies show that leaders establish legitimacy in terms of ethical foundation, respect, and honest relations with their followers (Walumbwa et al., 2008). In general, authentic leadership brings openness and boosts hope between leaders and assistants, which is essential for novelty and creativity. While its impact on innovation seems to be feasible, in earlier studies, and especially in the higher education literature, authentic leadership is usually considered slightly. This is also one of the basic requirements for administrative and staff development. Similarly, the authenticity of leaders has caught global attention in the past few years (Walumbwa et al., 2010).

Authentic leadership is well-defined as a model of leadership behavior, which uses and supports optimistic mental abilities and a positive moral atmosphere to cultivate advanced self-awareness, inner goodness, and balance of information processing and clarity of dealings (Walumbwa et al., 2008). Authentic leadership is a key topic of leadership research (Gardner et al. 2005), considering that it can explain the influence of leaders on human interaction in the organizational environment. The main characteristics of true leaders are that they have an optimistic inner state, including self-assurance, self-confidence, courage, and flexibility, and can also stimulate the expansion of these qualities of others. After real leadership emerged, investigators examined its impact on employee work consequences, such as Islamic work ethics and employee performance (Hsiung, 2012). Given that positive behaviors may change the status quo, bosses are not always welcoming them, and employees may stabilize benefits and fees before they become attractive to them (Parker and Collins, 2010). Working in organizations with true leaders, they are more likely to be 
gentle, willing to change, and workers are freer to participate in positive behavior. Nevertheless, experimental research that links true leadership to employee initiative is not enough.

In today's stormy work setting, ethics and performance problems require leaders to adopt novel ethical strategies (Avolio and Gardner, 2005). Experts and scholars have emphasized the importance of true leadership. Walumbwa et al. (2008) describes authentic leadership as a model of leadership behavior that uses and stimulates optimistic mental capabilities and has a positive moral atmosphere to promote superior self-awareness, adopted moral concepts, and appropriate adjusted information processing and interpersonal relationships transparency. Leaders work with followers to promote optimistic self-improvement. Avolio and Gardner (2005) argue that authentic leader behavior can improve supporter performance findings even in an unbalanced work setting.

Previous research has shown that true leaders have the potential to improve employee performance, organize citizenship behaviors', and empower employees (Leroy et al., 2012; Walumbwa et al., 2010). Besides, true leadership can have a progressive impact on team performance, team psychological capital, team beliefs, and team legitimacy (Hannah et al., 2011). Authentic leadership needs an atmosphere of seriousness about novelty and creativity and employee performance. However inadequate research has tested its role in novelty and employee performance, especially in the higher education sector. Černe et al. (2013) show that certain aspects of the innovation culture allow real leaders to impact the novelty policies of the organization, thereby increasing employee performance and organizational productivity. Many managers fail to realize that strong and true leaders with ethics and beliefs are the main factors that develop the culture of trust in the organization. Avolio and Gardner (2005) argue that true leaders will transfer their tasks and ideas to their colleagues, and they can empower them to exercise control and goal sense when performing their responsibilities. Authentic leaders demonstrate tolerance and calmness, an important feature of contextual control that enables authentic leadership to play a role in uniqueness (Yaverbaum and Sherman, 2008). The greater the authentic leadership, the greater the employee's innovation and creativity, which altimetry increases employee performance and productivity (Zhou et al. 2014). Also, true leadership plays a helpful role in the originality and innovation of employees and will affect the enlargement of new thoughts of employees. Authentic leadership can change employees' perceptions and inspire them to come up with solutions and different concepts to help them improve their own and organizational performance (Reiter-Palmon and Illies, 2004).

\section{RATIONALE OF THE STUDY AND PURPOSE}

In practice, employees don't need much time to understand the types of leaders they deal with. Real leaders are often respected because they can trust them without worrying about the surprise. Authentic leaders must obey their basic values and understand that workers may have different or even different perspectives, passions, and goals. Legitimacy is part of the character of a leader. However, some policies can drive inexperienced leaders in the right direction. It must be pointed out that men or women who adopt this leadership style must be honest about it. If it is just an act, it has nothing to do with authenticity. Authentic leadership strategies show that leaders establish legitimacy in terms of ethical foundation, admiration, and open relations with their supporters. In general, authentic leadership encourages openness and increases optimism between leaders and assistants, which is essential for innovation. While its impact on employee performance seems to be feasible, little consideration has been given to authentic leadership in previous research, especially in the literature of higher education. Therefore, the purpose of this study is to investigate the influence of authentic leadership on employee performance through the moderating role of Islamic work ethics.

\section{LITERATURE REVIEW}

\section{Authentic leadership}

According to organizational research, leadership plays a vital role in shaping organizational values and influencing organizational creation, development, rooting, and even destruction (Jaskyte, 2004). Leaders use modeling as a milestone in collective strategy, strengthen the sharing of rules and society, and promote shared ethics, clear practices, and behavioral patterns (Block, 2003). As a result, leaders can promote error management by creating environments that promote mutual support to respond to errors, communicate, comply with reporting procedures, disseminate early detection and monitoring practices, and share learning methods. Authentic leadership is optimistic leadership. Peterson and Luthans (2003) divide it into a process, which is portrayed from a positive psychological ability and a highly developed director background, showing that leaders and their subordinates have stronger self-awareness and selfregulated progressive behavior.

Authentic leadership includes four factors: self-awareness, balanced processing, internalized morality, and relationship transparency. Researchers have tested and empirically demonstrated these components, and the authentic leadership factors include the relationship between these components (Walumbwa et al., 2010). The first part of leadership is selfawareness, which clarifies the supremacy and boundaries of leaders and followers. It describes how followers understand their strengths and weaknesses, and how they use their weaknesses to influence their organization's followers. The second part is the balancing process, which includes the process of judging all relevant data and checking it before reaching any conclusions. The third element is the ethics employed; it means a positive management background, solid assistance, and qualifications for true leadership to guide fundamental decent values and principles. The last part is relationship transparency, which includes the equality and kindness of leaders in information distribution and emotions. 
Yukl (1989) pointed out that the culture of the organization has a wide impact on leadership, intentions, operations, team strength, credentials, crowd endurance, impact on commitments, and performance to achieve goals. Avolio and Gardner $\underline{(2005)}$ also present many differences between transformational leadership and authentic leadership theory, mystical leadership, and fascinating theory. Although there is an approximate connection between other leadership concepts and authentic leadership, authentic leadership has a unique module that makes it different from other leadership theories. While authentic leadership can gain broad theoretical support, other preliminary research is important for understanding the tools that authentic leaders use to accomplish follower behavior. More creative people have higher entrepreneurial goals (Mahmood et al., 2018). According to Abdullah et al. (2018), everyone can be a leader and influence followers through communication.

In current leadership theories, choosing true leadership as a forward-looking and prominent aspect of management culture reduces mistakes. At the same time, experts first emphasized the agility of real leaders, the clarity and directness of communication when they were conceptualized for the first time. These functions can be used as the basis for errors and the basis for learning and carrying beneficial self-development (Gardner et al., 2011). More specifically, the four aspects that may be particularly relevant to the mismanagement culture often describe true leadership: balance processing is the analysis of all related data objectively before building a decision and heeding to relevant aspects of the different perspectives before concluding. This is in line with the culture of error management, which emphasizes inspection and rapid identification of errors, and focuses on identifying feeble signs such as near-failures. Good internalization is related to great moral values. True leaders will firmly adhere to and recognize ethical principles, especially under common pressure. This is also related to the culture of error management, which inspires workers to take responsibility for their actions when they make mistakes, collaborate or make mistakes, and record individual or others' mistakes (Avolio and Gardner, 2005; Walumbwa et al., 2008). The transparency of the relationship is related to the emergence of the true identity of the leader. The relationship between the true leader and the admirer is consistent. This is consistent with a culture of poor management, which promotes the public release and dissemination of key information, individual opinions, and spirit, and even risks loss of expression. The last aspect is self-awareness, which has to do with true empathy for the strengths and weaknesses of true leaders, understanding of the effect of their actions on others, and the convenience of responding to others. Consistent with a culture of mismanagement, this aspect promotes a gradual and evolving relationship with the group and boosts their confidence and professional development (Deng et al., 2010). It also promotes the development of a culture that views experience (including failure) as a relevant knowledge resource and mistakes as a valuable response to improvement.

\section{Islamic work ethics}

Due to the expansion of business and globalization, researchers are increasingly interested in the field of ethical behavior and social duty. The term ethic usually refers to the study of the correctness and error of the individual. Professional ethics is a necessary condition for any organization in terms of upcoming functions, income, and maintenance (Nunnally, 1978). Besides, Rokhman (2010) pointed out that organizations can effort more successfully by assuming an ethical context that guides and helps organize their effort. Also, professional ethics back to economic expansion and mobilizes the success of organizations and their employees. The study believes that acceptance of professional ethics can highly predict in-service behavior and outcomes (Furnham, 1990). In more detail, work ethics is thought to replicate individuals' preferences for different aspects of their work, including their love of work and attitudes to financial and non-financial rewards. IWE originate from the Quran and the Prophet Muhammad SAW (pbuh)'s sayings and actions (Ali, 2008). The IWE is similar to the Islamic Hadari concept, which emphasizes effort and cooperation in negotiations. It is seen as a way of overcoming difficulties, avoiding the negligence of personal demands, and achieving balance in personal social life.

Beekun (1997) defines IWE as a moral principle that differentiates between correct and incorrect. Islamic work ethics is the way of exertion, and working methods are valuable treasures in human life. According to Marri (2012), the ethics of Islam demonstrates the good value of behavior, thinking, actions, or feeling. Rashid and Ibrahim (2008) pointed out that ethics is the result and outcome of Iman (belief), which appears in the worldview of Islamic human life. Besides, it is called akhlaq, a set of Islamic ethical standards that have basically been permitted in the Quran and stemmed from the behavior of the Prophet Muhammad SAW in his lifetime.

Muslim scholars also recognize the prominence of modern Islamic work ethics because it is part of Islamic thinking and constructive to every generation. Therefore, research on work ethics and its connection with personal and administrative features has received great attention in the literature (Yesil et al. 2012; Ali, 2008). IWE is a structure developed to integrate religious moral standards into one's career. Islam encourages professional participation and enables individuals to become energetic and reassuring actors in society. Islamic culture plays an essential part in building society and communities, and social relations are built with the help of companies and cooperation. The logical meaning of work ethics reveals that individuals' attitudes and behaviors toward the successful work of their organizations have been extensively studied, and may have filtered out the concepts of leadership and supervision. Similarly, the West also recognizes a lot of research on the value of work, focusing on Protestant work ethics (Weber, 1958). Weber conducted an intensified study of the origin of Western thought in PWE, that is, individuals had an "obligation" to work and 
confirmed the existence of the link between Protestantism and the advancement of present capitalism. The idea of IWE is still the foundation of Quraane-E-Kareem.

According to Al-Aidaros et al. (2013), Islamic work ethics is inclusive, accurate, and modest. The ethics in Islam is not only the spiritual ethics that determine behavior but also covers aspects of life such as physiology, spirit, morality, and even secular forms, such as intelligence, emotion, separate and collective. It is also accurate because it takes into account human capabilities. After all, God knows human strengths and weaknesses (Al-Qaradawi, 1996). Muslims also want to be able to perform all their duties ingeniously and cautiously. This is evidence of a statement by the Prophet Muhammad that it is clear that every Muslim must follow appropriately. The researchers distinguish some of the work-related claims of the Prophet Muhammad that work is the best form of worship. The basic principles of morality and righteousness must be the talents of economics, rules and obligations must be the essence of work, and work must maintain selfassurance and self-sufficiency (Ali, 2008).

An early study on the linkage between IWE and workplace attitudes is greatly regarded (Ali, 2008). There are few studies on the link between Islamic work ethics, personal and organizational variables (Yesil, 2012). The high degree of connection between IWE and role uncertainty and control points are becoming stronger. IWE also improves job satisfaction, organizational commitment, and employee performance (Yousef, 2000). High-level IWE securitization must be inclined to increase emotional organizational commitment. There are differences in Western work ethics. IWE is fascinated by individual participation in the public and society and the organization's responsibility to its workers (Khalil, 2009). WE are highly correlated with loyalty assessment (Ali and Al Kazmi, 2007). IWE requires that doing occupational in a dynamic setting will lead to upper performance and broader accomplishment. In the recent study of the association between IWE and innovation capabilities and the conclusions of this study, IWE has been greatly adopted in the public sector and has been accused of jointly announcing that the novelty of the Malaysian public sector is increasing. IWE measurements show a moderate and are positive correlation with the Innovation Capability Scale (Kumar and Rose, 2012). In terms of work ethics, Islam pays more emphasis on intentions than outcomes (Yousef, 2000; Ali and Al Kazmi, 2007).

\section{Employee performance}

According to Hawthorne's research, and much other research work on worker productivity emphasizes the fact that workers who are pleased with their work will have greater job performance than those who are unhappy with their work, thus achieving the highest job retention (Elnaga, 2013). Besides, it is said that if employees are dissatisfied and therefore lose motivation to perform well, they are more likely to change their organization or leave the job. Pleased and contented workers have upper employee performance, and organizations are more likely to encourage high-performing employees to achieve organizational goals (Rotundo and Sackett 2002). Employees are only happy when they feel capable of performing their work, which can be done through good leadership behavior and training programs.

Generally, employee performance is the degree to which an individual ends a task. Employee performance can be defined as all employees' participation in work (Bliese, 2002). Investigators are very optimistic about the possibility of defining and measuring employee performance. They began to realize that measuring the impact on work and performance supply is not easy. Mead (1998) pointed out that organizations showing moral orientation can establish an image in the community and form a progressive organizational culture. Bliese (2002) believes that ethical organizations may gain many advantages, such as efficiency, employee responsibility, communication efficiency, and competitive advantage.

Employee performance is critical for companies to do their utmost to support underperforming employees. Performance is divided into five components: planning, supervision, development, rating, and rewards (Jalil et al. 2010). In the planning phase, planning means set objectives, developing policies, and outline responsibilities and timelines to achieve aims. Monitoring is a phase in which the goal is seen as how a person can satisfy them. Monitoring means continuously calculating performance and continuously responding to workers and employed groups to attain their objectives. Continuous monitoring provides the opportunity to check how well workers are meeting programming standards and to make changes to unrealistic or challenging standards. In the development phase, employees should recover any bad performance seen during the company's work. During planning and supervision, the lack of performance becomes apparent and can be resolved.

Employee performance is defined as the behavior and actions of people who return to organizational goals (Rotundo and Sackett 2002). Avolio et al. (2004) believe that authentic leaders will affect supporters and continuously progress their effort and performance results by increasing their participation and job guarantees. So far, real leaders have expected the executive-level performance of company personnel in a study (Walumbwa et al., 2008), but limited research has correlated nurse performance with important organizational variables, and no studies have been able to start authentic leadership and employment-related performance. Some studies have presented that empowerment leadership and structural empowerment influence employee self-evaluation of their work efficiency (Spence Laschinger et al., 2015). Work efficiency is defined as an individual's perception of the complete usefulness of work (Spence Laschinger et al., 2015). Also, leadership is related to employee productivity, which is defined as the contribution of organizational results to the total value of assets used (McNeese-Smith 1997). Many researchers found a statistically significant positive 
correlation between leadership practices and employee productivity and performance (McNeese-Smith, 1997; Kouzes and Posner, 2006). Finally, Spence Laschinger and Wong (2015) also show a statistically significant positive correlation between leadership and employee performance.

Organizations rehearsing ethical values can improve organizational literacy and well-being, ensure the wealth of investors, and benefit the well-being of society (Jalil et al., 2010). An ethical workplace will produce job satisfaction, a sense of commitment, and worthy community placement. Forming a moral principle and putting it into practice creates an affluent environment. Ali (2008) pointed out that IWE emphasizes hard work, rivalry, faithfulness, transparency, and ethical responsibility. Also, Kumar and Rose (2012) point out that placing IWE into exercises, such as hard work, assurance, job devotion, job creativity, collaboration, and market fairness, has enabled some beneficial initiatives to be realized. These approaches are important human resources to regulate the effectiveness, productivity, and performance of employees.

IWE positively affects the organization's operations and employee performance (Jalil et al., 2010). Implementing IWE in the organization can promote the continuous expansion of the organization, improve customer satisfaction, and display a good business image. Likewise, effective implementation of IWE can lead to higher employee performance and broader prosperity (Ali and Al-Owaihan, 2008). In addition, some scholars ensure that the value of IWE improves the excellence and performance of employees and their organizations (Ahmad, 2011; Jalil et al., 2010).

The conceptual framework for authentic leadership, IWE, and employee performance are shown in Figure 1. It describes that authentic leadership as an independent variable, employee performance is a dependent variable, while, and IWE is a moderating variable. Hypotheses of the study are

Hypothesis 1: Authentic leadership has a significant impact on employee performance.

Hypothesis 2: Islamic work ethics has a significant impact on employee performance.

Hypothesis 3: There is a significant moderation effect of IWE on the association between authentic leadership and employee performance.

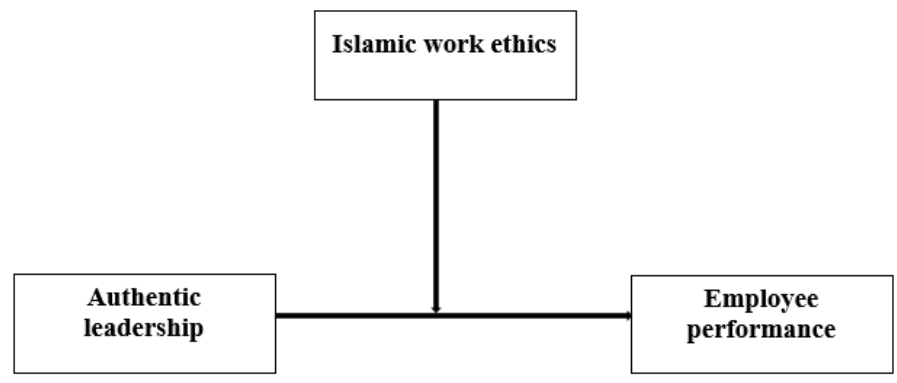

Figure 1: Conceptual Framework

Source: Nawaz et al., 2014

\section{RESEARCH METHOD}

The nature of this research is quantitative, studying several connections between independent and dependent variables. To collect information, a convenient sampling technique was used. This is a non-probability sampling technique. This method can be used to speed up research by attaining a huge number of complete questionnaires from participants quickly and economically. All universities in Peshawar were nominated for this study. Following the traditional approach of social science, we use questionnaires for primary data collection. We conducted a designed questionnaire to collect data for each variable in the proposed framework. We used well-established items from previous studies to measure the proposed variables. This questionnaire was designed according to the Likert scale-five-point with options; 1-strongly disagree to 5-strongly agree. Our target population was all the academic staff in private and public universities in the Peshawar region, therefore, the key respondents to this study were the academic staff. After assembling the information, we coded it in Excel 2010 and SPSS 16.0. Statistical tools, such as descriptive statistics, reliability, correlation, and regression analysis were used to support results through statistical proofs.

\section{Population and sample size of the study}

The population is the total number of all subjects, objects, or members that meet a series of norms (Polit \& Beck, 2004). In this study, the target population was all the employees who work in the private and public universities in the distract Peshawar, Pakistan. The general rule of thumb is to always use the largest possible sample. The larger the sample, the higher its representativeness, and the smaller the sample produces less accuracy because they may be less representative. The process of selecting a portion of the population to represent the entire population is called sampling.

In this study with the help of a convenience sampling technique 220 participants were selected from the entire population and requested to participate in the survey. The non-probability sampling technique was used for data 
selection. This technique will be used to make the research process faster by quickly and economically obtaining a large number of complete questionnaires from the university employees. The researchers found it easy to obtain participants, but the risk of bias is bigger than the random sample because each member of the population did not have equal opportunities to be included in the sample. The results obtained may not be extended to the entire population.

\section{Research instrument and measures}

The questionnaire is divided into two parts. The first part introduces the demographic characteristics of the respondents; the second part of the questionnaire tests the degree of agreement among respondents on IWE items, authentic leadership, and employee performance items. Respondents were asked to indicate that they agreed or disagreed with several statements on the five-point Likert scale, from $1=$ strongly disagree to $5=$ strongly agree. The questionnaire consisted of 40 items, 16 of which were used to assess authentic leadership developed by Walumbwa et al. (2008), 7 to measure employee performance developed by Williams and Anderson (1991), and 17 to assess IWE developed by Ali and Al-Owaihan (2008). In all cases, Likert's five-point scale range from 5 strongly agrees to 1 strongly disagrees were used.

\section{Demographic information}

Of the 220 questionnaires distributed, 200 have been returned with a completion rate of $90 \%$. In Table 1, male respondents accounted for $78 \%$ and female respondents accounted for $22 \% .42 \%$ of the respondents were under 30 years old, followed by $31-40$ years $32.5 \%$, and those older than 41 or above $25.5 \%$. In qualification, $32 \%$ of the respondents completed an M.Phil degree, $37 \%$ a Master's degree, and $31 \%$ completed a Bachelor's degree. According to the respondent's job experience in their existing organization, most of the respondents $38 \%$ have experience from 1-3 years, $28 \%$ worked for $4-7$ years, $16 \%$ of the respondents have work experience for above 7 years, while the remaining $18 \%$ have less than one-year job experience in their current organization.

Table 1: Demographic Profile

\begin{tabular}{llll}
\hline Variable labels & Value labels & Frequency & Percentage (\%) \\
\hline Gender & Male & 156 & 78 \\
\hline Age & Female & 50 & 22 \\
\hline & 21-30 years & 84 & 42 \\
\hline & 31-40 years & 65 & 32.5 \\
\hline Qualification & 41- above & 51 & 25.5 \\
\hline & M.Phil. & 64 & 32 \\
\hline Experience & Graduate & 74 & 37 \\
\hline & Bachelor & 62 & 31 \\
\hline & Less than 1 year & 36 & 18 \\
\hline & 1-3 year & 76 & 38 \\
\hline Total participants & 4-7 year & 56 & 28 \\
\hline
\end{tabular}

\section{RESULTS AND DISCUSSION}

\section{Reliability analysis}

The internal constancy of the data gathering tool is verified by measuring its validity and reliability. With the Cronbach $\alpha$ coefficient, the reliability of the scale can be measured. The higher the Cronbach $\alpha$ value, the higher the reliability. Alpha coefficients greater than 0.7 are acceptable (Nunnally, 1978). Table 2 indicates that all selected configurations have Cronbach's $\alpha$ coefficients above acceptable reliability levels.

Table 2: Reliability Analysis

\begin{tabular}{llll}
\hline Variables & Number of Items & Total Number & Cronbach's $\boldsymbol{\alpha}$ Value \\
\hline Authentic Leadership & 16 & 200 & 0.941 \\
\hline Islamic Work Ethics & 7 & 200 & 0.823 \\
\hline Employee Performance & 17 & 200 & 0.816 \\
\hline All variables (Final Measurement Model) & 40 & 200 & 0.935 \\
\hline
\end{tabular}

\section{Correlation analysis}

Table 3 lists the Pearson correlation coefficients. It can be seen from the matrix observations that there is a significant relationship among the variables, namely the dependent variable (employee performance), independent variables (authentic leadership), and intervening variable (IWE). Table 3 displays a positive correlation among all the variables. All values were significant in the 0.012 -tailed test. Independent variables (authentic leadership) were positively correlated with dependent variable (employee performance) $(\mathrm{r}=0.714, \mathrm{p}<0.01)$ and moderating variable (IWE) $(\mathrm{r}=$ 
$0.598, \mathrm{p}<0.01)$. It was also found that the moderating variable (Islamic work ethics) was also positively correlated with the dependent variable (employee performance) $(\mathrm{r}=0.524, \mathrm{p}<0.01)$.

Table 3: Correlation Analysis

\begin{tabular}{lllll}
\hline Variables & & AL & IWE & EP \\
\hline \multirow{2}{*}{ Authentic Leadership (AL) } & Pearson Correlation & 1 & $.598^{* *}$ & $.714^{* *}$ \\
\cline { 2 - 5 } & Sig. (2-tailed) & & .000 & .000 \\
\hline \multirow{2}{*}{ Islamic Work Ethics (IWE) } & Pearson Correlation & $.598^{* *}$ & 1 & $.524^{* *}$ \\
\cline { 2 - 5 } & Sig. (2-tailed) & .000 & & .000 \\
\hline \multirow{2}{*}{ Employee Performance (EP) } & Pearson Correlation & $.714^{* *}$ & $.524^{* *}$ & 1 \\
\cline { 2 - 5 } & Sig. (2-tailed) & .000 & .000 & \\
\hline
\end{tabular}

** Correlation is significant at the 0.01 level $(2$ tailed $)$

\section{Regression weight}

To examine the variability of one variable due to another variable, regression analysis was used. It was used to examine the changes in employee performance due to authentic leadership and IWE. Regression analysis results confirmed that there was a positive association between the independent and dependent variables. The value of $(\beta=0.613, t-v a l u e=$ $5.735, \mathrm{p}<0.05$ ) indicates that the independent variable (authentic leadership) caused a $61.3 \%$ variation in the dependent variable (employee performance). According to the results of the current study confirm hypothesis 1 . Similarly, authentic leadership has also a positive significant influence on Islamic work ethics $(\beta=0.359$, t-value $=4.068, p<0.05)$, which also confirms our second hypothesis. Authentic leadership contributes almost $36 \%$ to Islamic work ethics. Additionally, it is also noted that the interactive association of authentic leadership and IWE significantly influence employee performance $(\beta=0.118$, t-value $=1.385, \mathrm{p}<0.05)$, which also confirms our third hypothesis. Based on the results, the interactive impact of authentic leadership and IWE contribute almost $12 \%$ to employee performance.

Table 4: Regression Weights

\begin{tabular}{lllllll}
\hline Hypothesis & Hypothesized Effect & Std.Estimate & S.E. & C.R. & P & Label \\
\hline 1 & $\mathrm{EP} \leftarrow \mathrm{AL}$ & 0.613 & 0.105 & 5.735 & $* * *$ & $\sqrt{ }$ \\
\hline 2 & $\mathrm{IWE} \leftarrow \mathrm{AL}$ & 0.351 & 0.056 & 4.068 & $* * *$ & $\sqrt{ }$ \\
\hline 3 & $\mathrm{EP} \leftarrow \mathrm{AL}$ X IWE & 0.114 & 0.078 & 1.385 & 0.011 & $\sqrt{ }$ \\
\hline
\end{tabular}

Note: Significance level $* * \mathbf{P}<0.01$

\section{DISCUSSION AND CONCLUSION}

Our research objectives to investigate the influence of authentic leadership on employee performance. The study also directed to investigate the moderating role of IWE in the association between authentic leadership and employee performance. Our study targeted academic staff in higher education institutions in the Peshawar region. Regression analysis was performed on 220 valid observations. The main model results show that authentic leadership is positively correlated with employee performance. Similarly, also indicated that authentic leadership positively influences employee performance and can change organizational culture and encourage worker performance. This suggests that authentic leaders and their behaviors can create an environment of trust and promote employee performance. Similarly, authentic leadership significantly influences IWE. The interactive effect of authentic leadership and Islamic work ethics on employee performance was found significantly. Therefore, leaders must take steps to confirm that psychological care is maintained through personal autonomy and support for advanced values. It is also essential to strengthen its significance based on Islamic standards. Leaders should also provide employees with more opportunities to connect directly with recipients at work to fully recognize the impact of their effort on others.

\section{LIMITATION OF THE STUDY}

It is hard to find research without restrictions. This study has some limitations. The first restriction of this research was that it was performed using eight universities located in Peshawar, which limited our capability to generalize the results of this study. An upcoming study should investigate an illustrative sample to make our results more applicable across the country. The second restriction, this research was directed at developing countries like Pakistan. The coming study should investigate this miracle in other universities in more developed countries. The third restriction, in this study the samples were taken from only eight universities in Peshawar, hence the findings may not apply to other areas. An upcoming study should investigate our structure in other areas to test its accuracy in forecasting novelty in new areas. The last restriction, only one leadership style was investigated in this research. Therefore, upcoming research should explore other styles of leadership.

\section{SUGGESTIONS}

Despite the brief hints in the previous section, future studies should imitate the same research model across departments to see if comparable outcomes can be made. Besides, more leadership styles should be considered. In this study, Islamic 
work ethics was used as the moderating variable. Future studies may use other moderating variables between these two structures. Furthermore, upcoming researchers may use learning organizations as mediators or moderators' variables. Adding other moderation variables, such as attitude, training, and trust can be very useful. Trust can greatly move employee performance, especially in Asian counties.

\section{AUTHORS CONTRIBUTION}

Dr. Amjad Ali: He has contributed majorly in conceptualizing the introduction and literature review of this study. He has also helped enumerators in conducting interviews with respondents. He has good tacts to conduct interviews in local languages as well.

Dr. Shahzad Mushtaq: The second author, has contributed majorly in conceptualizing the area of study, targeted audience, discussions and conclusion, recommendation, limitations, and future research directions.

Dr.Muhammad Asif and Dr. Muhammad Qasim Maqbool: Have contributed to this study in data collection from the employees of higher education sectors of desired districts of Peshawar.

Dr. Umer Bin Khalid: He has developed the research design of this study and research methodology. He has analyzed the data by using SPSS.

\section{REFERENCES}

1. Al-Douri, J. A., Aldabbagh, I., Mohammad, M. M., \& Qawasmeh, R. (2020). The impact of Islamic work ethics on job performance with mediating role of intrinsic motivation. Academy of Strategic Management Journal, 19(2), 1-11.

2. Abdullah, M. I., Sarfraz, M., \& Kazmi, S. M. H. (2018). Traits of leadership for efficacious communication of Project Management in Software Industry of Pakistan. Khazar Journal of Humanities and Social Sciences, 21(1), 2223-2613. https://doi.org/10.5782/2223-2621.2018.21.1.5

3. Ali, A. J., \& Al-Owaihan, A. (2008). Islamic work ethic: a critical review. Cross-cultural management: An international Journal, 15(1), 5-19. https://doi.org/10.1108/13527600810848791

4. Avolio, B. J., \& Gardner, W. L. (2005). Authentic leadership development: Getting to the root of positive forms of leadership. The leadership quarterly, 16(3), 315-338. https://doi.org/10.1016/j.leaqua.2005.03.001

5. Al-Aidaros, A. H., \& Mohd Shamsudin, F. (2013). Ethics and ethical theories from an Islamic perspective. International Journal of Islamic Thought, 4, 1-13. https://doi.org/10.24035/ijit.04.2013.001

6. Al-Qaradawi, Y. (1996). The general characteristics of Islam. Beirut: Darul Al-Research Publication.

7. Ahmad, M. S. (2011). Work ethics: an Islamic perspective. Journal of Human Sciences, 8(1), 850-859.

8. Ali, A. J., \& Al-Kazemi, A. A. (2007). Islamic work ethic in Kuwait. Cross cultural management: An international Journal, 14(2), 93-104. https://doi.org/10.1108/13527600710745714

9. Avolio, B. J., Gardner, W. L., Walumbwa, F. O., Luthans, F., \& May, D. R. (2004). Unlocking the mask: A look at the process by which authentic leaders impact follower attitudes and behaviors. The leadership quarterly, 15(6), 801-823. https://doi.org/10.1016/j.leaqua.2004.09.003

10. Block, L. (2003). The leadership-culture connection: an exploratory investigation. Leadership \& Organization Development Journal, 24(6), 318-334. https://doi.org/10.1108/01437730310494293

11. Beekun, R. I. (1997). Islamic business ethics (No. 2). International Institute of Islamic Thought (IIIT). https://doi.org/10.2307/j.ctvk8w1zv

12. Bliese, P. D., \& Jex, S. M. (2002). Incorporating a mulitilevel perspective into occupational stress research: Theoretical, methodological, and practical implications. Journal of occupational health psychology, 7(3), 265. https://doi.org/10.1037/1076-8998.7.3.265

13. Černe, M., Jaklič, M., \& Škerlavaj, M. (2013). Authentic leadership, creativity, and innovation: A multilevel perspective. Leadership, 9(1), 63-85. https://doi.org/10.1177/1742715012455130

14. Den Hartog, D. N., \& Belschak, F. D. (2012). When does transformational leadership enhance employee proactive behavior? The role of autonomy and role breadth self-efficacy. Journal of Applied Psychology, 97(1), 194. https://doi.org/10.1037/a0024903

15. Deng, B.-H., Bligh, M. C., \& Kohles, J. C. (2010). To err is human, to lead is divine? The role of leaders in learning from workplace mistakes. In B. Schyns \& T. Hansbrough (Eds.), When leadership goes wrong: Destructive leadership, mistakes, and ethical failures, IAP Information Age Publishing, 445-475.

16. Elnaga, A., \& Imran, A. (2013). The effect of training on employee performance. European Journal of Business and Management, 5(4), 137-147.

17. Furnham, A. (1990). The Protestant work ethic: The psychology of work-related beliefs and behaviours. Routledge, ISBN- 0415017041

18. Gardner, W. L., Avolio, B. J., \& Walumbwa, F. O. (Eds.). (2005). Authentic leadership theory and practice: Origins, effects and development (Vol. 3). Elsevier.

19. Gardner, W. L., Cogliser, C. C., Davis, K. M., \& Dickens, M. P. (2011). Authentic leadership: A review of the literature and research agenda. The leadership quarterly, 22(6), 1120-1145. https://doi.org/10.1016/j.le aqua.2011.09.007 
20. Hsiung, H. H. (2012). Authentic leadership and employee voice behavior: A multi-level psychological process. Journal of business ethics, 107(3), 349-361. https://doi.org/10.1007/s10551-011-1043-2

21. Hannah, S. T., Avolio, B. J., \& Walumbwa, F. O. (2011). Relationships between authentic leadership, moral courage, and ethical and pro-social behaviors. Business Ethics Quarterly, 21(4), 555-578. https://doi.org $/ 10.5840 /$ beq 201121436

22. Jensen, S. M., \& Luthans, F. (2006). Relationship between entrepreneurs' psychological capital and their authentic leadership. Journal of managerial issues, 254-273.

23. Jaskyte, K. (2004). Transformational leadership, organizational culture, and innovativeness in nonprofit organizations. Nonprofit Management and Leadership, 15(2), 153-168. https://doi.org/10.1002/nml.59

24. Jalil, A., Azam, F., \& Rahman, M. K. (2010). Implementation mechanism of ethics in business organizations. International Business Research, 3(4), 145. https://doi.org/10.5539/ibr.v3n4p145

25. Khalil, M., \& Abu-Saad, I. (2009). Islamic work ethic among Arab college students in Israel. Cross cultural management: An international Journal, 16(4), 333-346. https://doi.org/10.1108/13527600911000320

26. Kumar, N., \& Rose, R. C. (2012). The impact of knowledge sharing and Islamic work ethic on innovation capability. Cross Cultural Management: An International Journal, 19(2), 142-165. https://doi.org/10.1108/13 527601211219847

27. Kouzes, J. M., \& Posner, B. Z. (2006). The leadership challenge (Vol. 3). John Wiley \& Sons.

28. Leroy, H., Palanski, M. E., \& Simons, T. (2012). Authentic leadership and behavioral integrity as drivers of follower commitment and performance. Journal of business ethics, 107(3), 255-264. https://doi.org/10.100 7/s10551-011-1036-1

29. Morrison, A. (2001). Integrity and global leadership. Journal of Business Ethics, 31(1), 65-76. https://doi.org/10.1023/A:1010789324414

30. Mahmood, A., Sarfraz, M., Ramzan, M. A., \& Abdullah, M. I. (2018). Impact of creativity on entrepreneurial intentions through Self-efficacy. International Journal of Humanities and Social Development Research, 2(1), $52-73$.

31. McNeese-Smith, D. K. (1997). The influence of manager behavior on nurses' job satisfaction, productivity, and commitment. JONA: The Journal of Nursing Administration, 27(9), 47-55. https://doi.org/10.1097/00005110199709000-00011

32. Marri, M. Y. K., Sadozai, A. M., Zaman, H. M. F., \& Ramay, M. I. (2012). The impact of Islamic work ethics on job satisfaction and organizational commitment: a study of agriculture sector of Pakistan. International Journal of Business and Behavioral Sciences, 2(12), 32-45.

33. Mead, R. (1998). International management. Blackwell, p-478, ISBN-0631200037.

34. Nunnally J.C. (1978) An Overview of Psychological Measurement. In: Wolman B.B. (eds) Clinical Diagnosis of Mental Disorders. Springer, Boston, MA, 97-146. https://doi.org/10.1007/978-1-4684-2490$\underline{4} 4$

35. Parker, S. K., \& Collins, C. G. (2010). Taking stock: Integrating and differentiating multiple proactive behaviors. Journal of management, 36(3), 633-662. https://doi.org/10.1177/0149206308321554

36. Peterson, S. J., \& Luthans, F. (2003). The positive impact and development of hopeful leaders. Leadership \& Organization Development Journal, 24(1), 26-31. https://doi.org/10.1108/01437730310457302

37. Polit, D. F., \& Beck, C. T. (2004). Nursing research: Principles and methods. Lippincott Williams \& Wilkins.

38. Reiter-Palmon, R., \& Illies, J. J. (2004). Leadership and creativity: Understanding leadership from a creative problem-solving perspective. The Leadership Quarterly, 15(1), 55-77. https://doi.org/10.101 6/j.leaqua.2003.12.005

39. Rokhman, W. (2010). The effect of Islamic work ethics on work outcomes. EJBO-Electronic Journal of Business Ethics and Organization Studies. Vol. 15 (1) 9. Retrieved from http://ejbo.jyu.fi

40. Rotundo, M., \& Sackett, P. R. (2002). The relative importance of task, citizenship, and counterproductive performance to global ratings of job performance: A policy-capturing approach. Journal of applied psychology, 87(1), 66. https://doi.org/10.1037/0021-9010.87.1.66

41. Rashid, M. Z., \& Ibrahim, S. (2008). The effect of culture and religiosity on business ethics: A cross-cultural comparison. Journal of Business Ethics, 82(4), 907-917. https://doi.org/10.1007/s10551-007-9601-3

42. Spence Laschinger, H. K., \& Nosko, A. (2015). Exposure to workplace bullying and post-traumatic stress disorder symptomology: the role of protective psychological resources. Journal of nursing management, 23(2), 252-262. https://doi.org/10.1111/jonm.12122

43. Thomas, G., Martin, R., \& Riggio, R. E. (2013). Leading groups: Leadership as a group process. Sage publications. https://doi.org/10.1177/1368430212462497

44. Walumbwa, F. O., Avolio, B. J., Gardner, W. L., Wernsing, T. S., \& Peterson, S. J. (2008). Authentic leadership: Development and validation of a theory-based measure. Journal of management, 34(1), 89-126. https://doi.org/10.1177/0149206307308913

45. Walumbwa, F. O., Hartnell, C. A., \& Oke, A. (2010). Servant leadership, procedural justice climate, service climate, employee attitudes, and organizational citizenship behavior: a cross-level investigation. Journal of applied psychology, 95(3), 517. https://doi.org/10.1037/a0018867 
46. Weber, M. (1958). The Protestant ethic and the spirit of capitalism, trans. T. Parsons. Charles Scribner's Sons.[SA].

47. Williams, L. J., \& Anderson, S. E. (1991). Job satisfaction and organizational commitment as predictors of organizational citizenship and in-role behaviors. Journal of management, 17(3), 601-617. https://doi.org/1 $0.1177 / 014920639101700305$

48. Yaverbaum, E., \& Sherman, E. (2008). The Everything Leadership Book: Motivate and inspire yourself and others to succeed at home, at work, and in your community. Simon and Schuster.

49. Yukl, G. (1989). Managerial leadership: A review of theory and research. Journal of management, 15(2), 251289. https://doi.org/10.1177/014920638901500207

50. Yousef, D. A. (2000). Organizational commitment as a mediator of the relationship between Islamic work ethic and attitudes toward organizational change. Human relations, 53(4), 513-537. https://doi.org/10.11 77/0018726700534003

51. Yesil, S., \& Dogan, O. (2012). An investigation into the implications of Islamic work ethic (IWE) in the workplace. Journal of Economics and Behavioral Studies, 4(11), 612-624. https://doi.org/10.22610 /jebs.v4i11.362

52. Zhou, J., Ma, Y., Cheng, W., \& Xia, B. (2014). Mediating role of employee emotions in the relationship between authentic leadership and employee innovation. Social Behavior and Personality: an international journal, 42(8), 1267-1278. https://doi.org/10.2224/sbp.2014.42.8.1267 